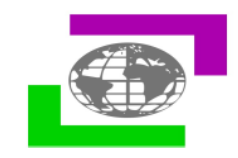

\title{
A PROSPECTIVE STUDY ON DRUG UTILIZATION IN OBSTETRIC PROCEDURES WITH EMPHASIS ON ANTIBIOTIC USAGE AT A TERTIARY CARE HOSPITAL
} Shikha Sachdeva ${ }^{1}$, Aarti Chaudhary ${ }^{1}$, Parminder Nain*1, Unmesh Santpur ${ }^{2}$

${ }^{1}$ Department of Pharmacy Practice, M.M. College of Pharmacy, Maharishi Markandeshwar (Deemed to be University), Mullana-Ambala (Haryana)

${ }^{2}$ Department of Obstetrics \& Gynaecology, MMMISR, Maharishi Markandeshwar (Deemed to be University), Mullana-Ambala (Haryana)

Article Info: Received 20 June 2019; Accepted 16 September. 2019

DOI: https://doi.org/10.32553/jbpr.v8i5.651

Corresponding author: Dr. Parminder Nain

Conflict of interest statement: No conflict of interest

ABSTRACT:

Background: Antibiotics are largely prescribed drugs in all major surgical procedures due to high prevalence of infections that has been increase in expenditure and increases antibacterial resistance. Drug utilization studies help to identify and overcome the misuse of antibacterial in prescribing pattern. Hence, the aim of this study was to evaluate the antibiotics utilization patterns in obstetric procedures.

Methods: It is a prospective observational study carried out in department of obstetrics and gynecology, of a multispecialty teaching hospital (Haryana) after obtaining permission from the IEC. The prescriptions were assessed for patient's demographic data, antimicrobial preference, dose, duration, and route of administration. Categorization of drugs according to Food and Drug Administration (FDA), and rationality score as per the World Health Organization (WHO).

Results: During six month study period 120 patients were included into study. The mean age of women undergoing Csection procedure was $27.79 \pm 2.78$ years. The maximum $(90.83 \%)$ length of hospital stay was 2 week by women under $\mathrm{C}$ section procedure. The single antibiotic therapy (ceftriaxone - 53.33\%) was the most commonly prescribed antibiotic as prophylaxis but in post- operative prescription orders, triple antibiotic combination therapy (ceftriaxone, metronidazole with gentamycin) was maximum (62.50\%) prescribed antibiotic. Parenteral route (96.09\% in pre-operative and $59.40 \%$ in post-operative) was most common route for antibiotic administration. Out of 2216 drugs, branded drugs were 1893 (85.42\%) and generic drugs were 323 (14.58\%).

Conclusion: The present study facilitates the rational use of ceftriaxone as prophylaxis in C-section and triple antibiotic combination therapy as post-operative by the gynaecologists. These antibiotics are most effective without any adverse effect on mother and fetus when use in recommended dose and frequency during obstetric procedures.

Keywords: Antibiotics, Caesarean section delivery, Drug utilization study

\section{INTRODUCTION}

Drug utilization study is a structural and systemic process used to assess the quality of drug therapy by engaging in the review of drug prescribing, dispensing and use of medication among patient and society with special emphasis on the medical rationality, authentic, social and economic consequences. ${ }^{1}$ It is also referred as drug utilization evaluation (DUE) or medication review utilization (MUE). ${ }^{2}$ The main objective of DUE is to review prescribing patterns and uses of drugs with certain guidelines in the treatment of certain disease. ${ }^{3}$ These studies helps in identification of problems related to drug prescribing and also provide data to prescribers to overcome these problems. ${ }^{4}$

Pregnancy is a special physiological condition, where drug treatment presents a special concern because the physiology of pregnancy affects the pharmacokinetics of medications used and in addition to the mother, the health and life of her unborn child is also at stake. ${ }^{5}$ There are two types of delivery options: caesarean delivery and normal delivery. Caesarean section is a surgical procedure which is used to deliver a baby. In this procedure the surgical incisions are made on the abdominal and uterine wall to separate the mother and the 
foetus. ${ }^{6}$ A caesarean section is indicated when delivery is required and cannot be performed vaginally because it will take too long or because it will endanger the mother or the foetus. A caesarean delivery is necessary if the women is having more than one foetus; the labour not progressing normally; the health of the foetus is in danger; the size of the foetus is too large; the foetus is not in right position (like breech presentation); the mother is suffering from any infection like HIV or herpes; the foetus is not getting enough oxygen. According to some studies $85 \%$ of caesarean sections are planned but $15 \%$ are done in the case of emergency. The increasing rate of C-sections is thought to be mainly to change the risk profile both for the mother and their foetus. ${ }^{7}$

Cesarean delivery is frequently complicated by surgical site infections (SSIs), endometritis and urinary tract infection. There is 5-24 fold greater risk for infection in the caesarean delivery than the vaginal delivery. Antibiotics are oftently used to minimize the risk of infection in caesarean delivery. ${ }^{8}$ Evidence based guidelines recommended the use of prophylactic antibiotics prior to surgical incision but an exception is made for cesarean delivery, where narrow-range antibiotics are administered post umbilical cord clamping because of putative neonatal benefit. If prophylaxis is given after cord clamping, then local surgical site infection should be monitored and a change in antibiotics that are given before incision if the rates are higher than expected. However, recent evidence supports the use of pre-incision, broadspectrum antibiotics which result in less maternal morbidity with no disadvantage to the neonate. ${ }^{9}$ In most of the healthcare setting the post natal patient receives number of anti-biotic therapy for about 7- 10 days. Use of these drugs for long term increase the cost or economic burden on the patient, extra work load on staff and results in their resistance. ${ }^{10}$ The majority of the studies suggest that a single dose is effective but for lengthy procedures (more than 3 hours) the dose should be repeated at intervals of 1 or 2 times the half-life of the drug. The most commonly prophylactic antibiotic in C-section and normal delivery is first generation cephalosporin i.e. cefazolin 1-2 gm IV. It is under pregnancy category $B$ drug and its half-life is 1.8 hours. It is broad spectrum for gram positive and gram negative organisms. It should be administered before 30 minutes of the incision.
According to research studies, twice the normal dose of prophylaxis is given in obese patients who have $\mathrm{BMI}>35$. The patients who are allergic to cephalosporin the alternative drug of choice is clindamycin $600 \mathrm{mg}$ IV or erythromycin $500 \mathrm{mg}$ IV. $^{11}$ Since there are very few studies which describe the utilization of drugs as prophylaxis and post-operatively; this study was conducted to provide the drug utilization pattern in preoperative and post-operative wards and to increase the rational use of drug to improve patient quality of life. So this study was undertaken in our tertiary care hospital to evaluate the utilization pattern of drugs and to monitor the rationality of the usage of medications among the prophylaxis and post- operative gynaecological patients.

\section{RESEARCH METHODOLOGY}

The present study was a prospective observational study which was attempted to find out the frequently prescribed pre-operative and postoperative antibiotics by the physician/surgeon in Csection. The study was conducted in a tertiary care teaching hospital. After obtaining approval and clearance from the Institutional Ethics Committee (IEC), a total of one hundred twenty $(n=120)$ inpatient prescription records were collected from November 2016 to April 2017. The patients those who fulfilled inclusion criteria were included in this study.

Inclusion criteria - All patients undergoing commonly performed gynaecological C-section operations and patient above 18 years and below 40 years of age

Exclusion criteria - (i) Patient discharged against medical advice (ii) Patient who were referred to higher centre were excluded from the study. (iii) Patient who were not consenting for the study. (iv) Psychiatric illness. (v) Patients with HIV/ Herpes simplex virus.

\section{Data collection analysis}

A case report form was used to collect data of the patient's demographic details like patient age, weight of patient, reason for admission, complication of pregnancy and delivery, stay of patient in hospital, past medical history, co-morbid conditions, prescribing pattern for antibiotic drugs and other prescribing drugs after delivery. In order 
to study the prescriptions were assessed for patient's antimicrobial preference in pre and postoperative, dose, duration, route of administration, branded/Generic and categorization of drugs according to Food and Drug Administration (FDA).

\section{Statistical methods}

The present study was analysed by descriptive and inferential statistical analysis (mean \pm SD). Microsoft word and excel to generate graphs, tables etc. have been used.

\section{RESULTS}

In this study, total number of encounters were one hundred twenty $(n=120)$. The mean age of women undergoing C-section procedure was $27.79 \pm 2.78$ years. The patients most commonly were from the age group of $21-25$ years $(54.83 \%)$ followed by 26 30 years $(23.33 \%), 31-35$ years $(16.67 \%)$, least were of the age group $36-40$ years (5.17\%). (Figure -1)

Types of surgery in caesarean delivery - The patient were examined and diagnosed, had underwent different types of surgery in caesarean delivery. Among lower segment caesarean section, most commonly performed surgery was emergency Lower Segment Caesarean Section (LSCS) (73.33\%), followed by elective LSCS (12.50\%), Emergency LSCS with B/L TL (10\%) and elective LSCS with B/L $\mathrm{TL}(4.17 \%)$ as shown in table-1.

Indications of C- Section - The indications for Csection included foetal distress (28.33\%), cephalopelvic disproportion (5\%), oligohydraminos (4.17\%), breech presentation (18.33\%) and gestational hypertension (3.33\%) as shown in figure 2 .

Length of hospital staying (days) in C- section Out of 120 patients, 109 patients (90.83\%) were staying in hospital for 2 weeks, 6 patients (5\%) were staying for 3 weeks, 4 patients (3.33\%) were staying for 4 weeks and 1 patient $(0.83 \%)$ was staying for less than a week (table-2).

Distribution of drugs on the basis of pre and postoperative orders in C-section ( $n=2216)$ - Among total number of drugs (2216), post drugs were 1749 (78.93\%) and pre drugs were 467 (21.07\%) in caesarean delivery as shown in figure-3

Antibiotics in pre-operative and post -operative orders of C-section: Drugs prescribed to the inpatients who had undergone $\mathrm{C}$-section surgeries in order to pre-operative and post-operative are shown in the table 3 and table 4 respectively.

Table 3 represents that the prescribed antibiotics in pre-operative orders of C-section as single therapy (Inj. ceftriaxone) was $53.33 \%$, dual therapy (Inj. ceftriaxone and Inj. metronidazole) was $12.50 \%$ and in triple therapy (Inj. ceftriaxone, Inj. metronidazole and Inj. gentamycin) was 5.83\%.

Post-operative orders of C-section represents in table 4 , that the prescribed antibiotics as dual therapy (Inj. ceftriaxone and Inj. metronidazole) was $19.16 \%$ most commonly prescribed, in triple therapy (Inj. ceftriaxone, Inj. metronidazole and Inj. gentamycin) was prescribed $62.50 \%$ and in quadruple therapy (Inj. ceftriaxone, Inj. metronidazole, Inj. gentamycin and Inj. amoxicillin with clavulanic acid) was prescribed $0.83 \%$.

Route of antibiotics administration in pre and post-operative orders of C-section - Parenteral route (injection) $96.09 \% \quad(n=123)$ and $59.40 \%$ $(n=335)$ were the most commonly prescribed route of administration for antibiotics as compared to oral (Tablets) $3.91 \%(n=5)$ and $40.60 \%(n=229)$ in pre-operative and post-operative prescription orders respectively of $\mathrm{C}$-section procedures. (Table5)

Prescription of Antacids in C-section - The next commonly prescribed drug was antacids. The percentage of antacid prescribed in pre-orders of C-section was injection ranitidine (73.96\%), tablet ranitidine (23.96\%) and syrup aluminium hydroxide with magnesium hydroxide (2.08\%). (Figure -4)

The most commonly prescribed antacids was observed as injection ranitidine $47.5 \%(n=57)$ and the percentage of other antacids drugs were tablet ranitidine $38.3 \%(n=46)$, tablet pantoprazole $8 \%$ $(n=9)$, tablet pantoprazole with domperidone $4.17 \%(n=5)$, injection pantoprazole $1.66 \%(n=2)$, syrup aluminium hydroxide with magnesium hydroxide $0.83 \%(n=1)$ in post-operative orders of C-section. (Figure -5)

Prescription of NSAIDS as analgesic in C-section The most commonly prescribed analgesics were NSAIDs. The patients among who received various NSAIDS after caesarean section, it was observed that injection diclofenac sodium was $48.15 \%$ ( $n=$ 117), tablet diclofenac sodium with serratiopeptidase was $27.98 \% \quad(n=68)$, tablet ibuprofen with paracetamol was $17.28 \%(n=42)$, 
tablet paracetamol was $4.11 \%(n=10)$ and tablet diclofenac sodium was $2.46 \%$ ( $n=6$ ) (Table 6).

Distribution of drugs prescribed in brand and generic - The prescribed drugs were categories on the basis of generic and brand. Out of 2216 prescribed drugs, the branded drugs were 1893 (85.42\%) and generic drugs were 323 (14.58\%) in caesarean section as shown in figure 6 .

Distribution of prescribed drugs from essential drug list - The prescribed drugs were catego ries accordance to WHO essential drug list.( Figure -7)

In caesarean delivery out of 2216 prescribed drugs, the maximum drugs $(90.25 \%)$ were in the category of List of Essential Medicines.

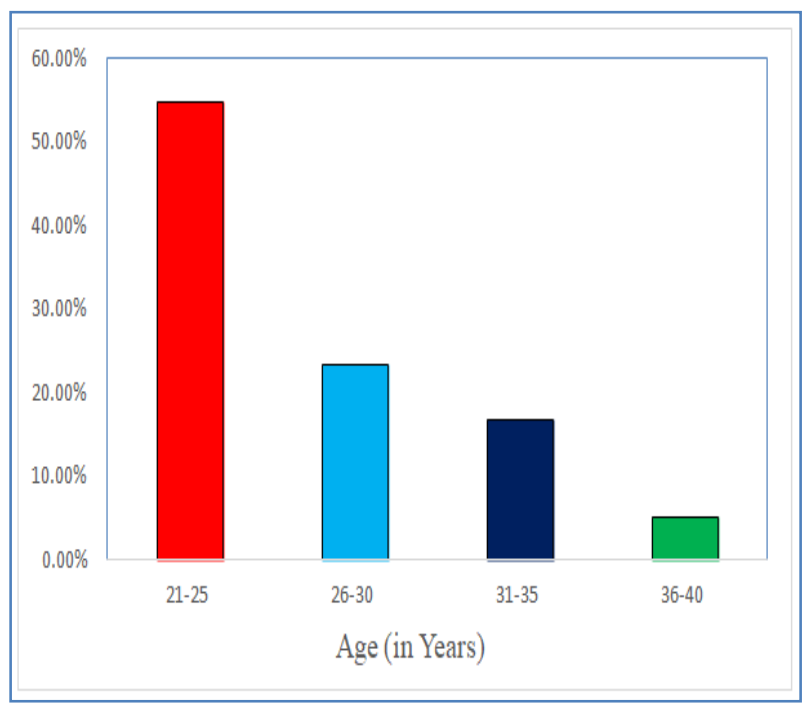

Figure 1: Age wise distribution of patients in CSection

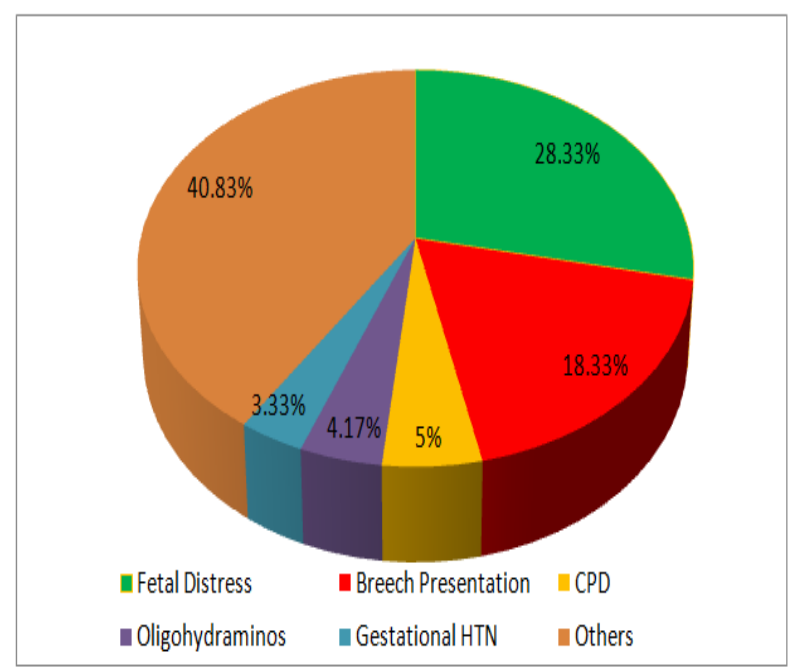

Figure 2: Indications of C- Section

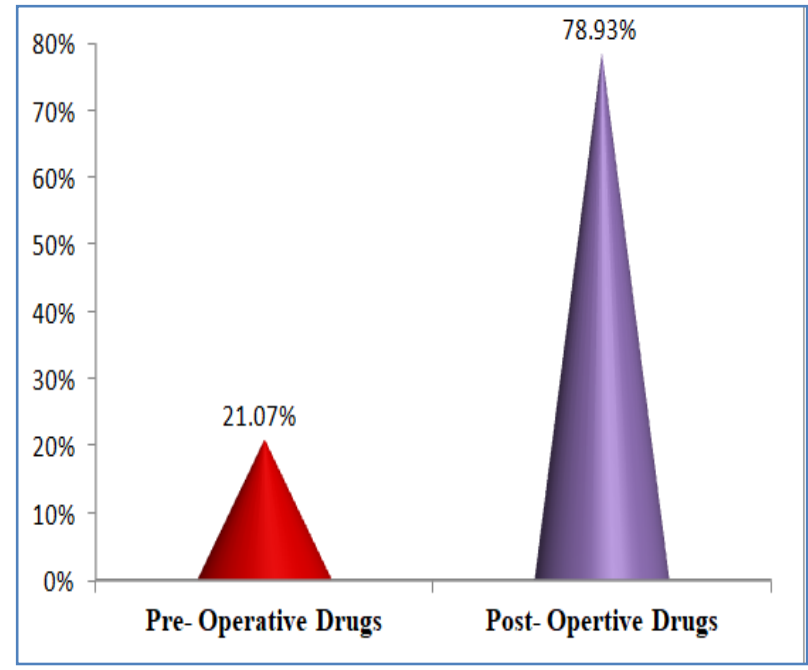

Figure 3: Prescribed drugs in pre and postoperative procedure of caesarean delivery

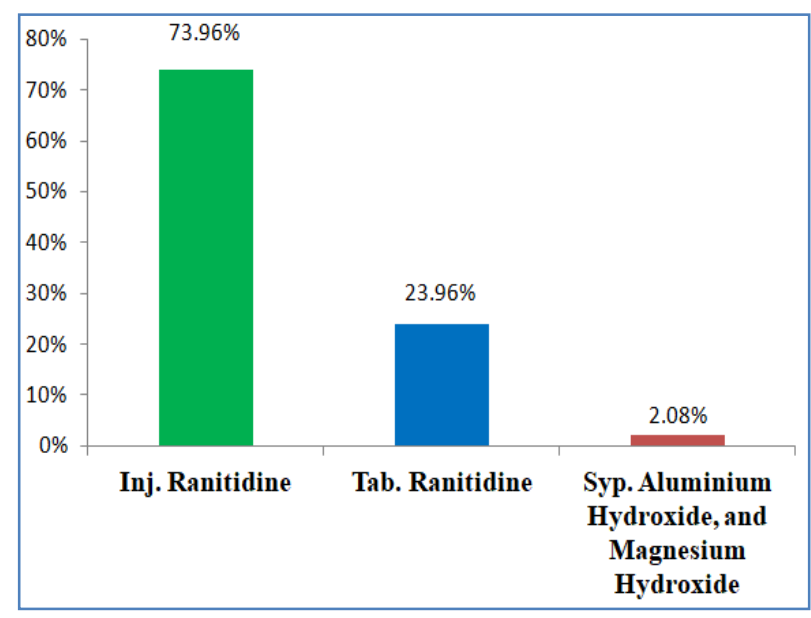

Figure 4: Categorization of antacids in preoperative orders of C-section

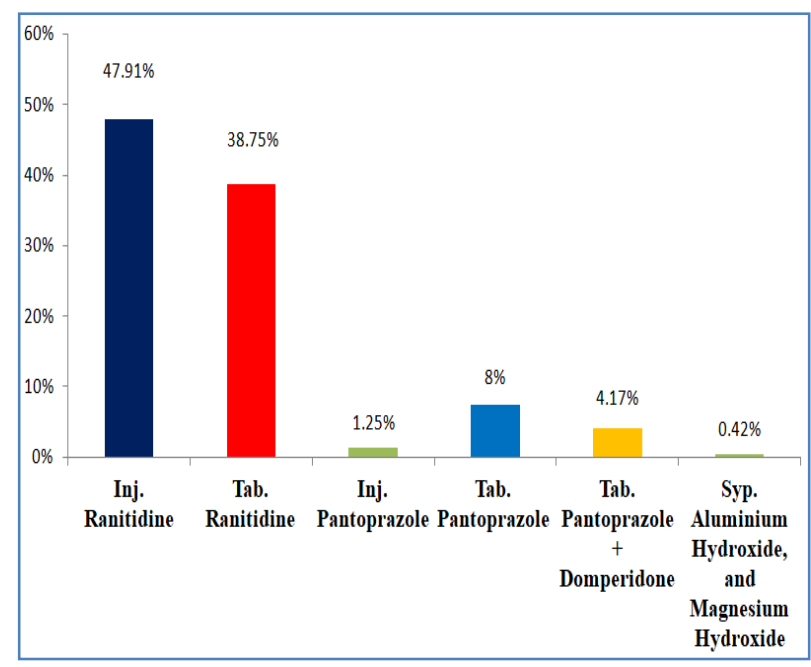

Figure 5: Categorization of antacids in postoperative orders of C-section 
Dr. Parminder Nain I et al., Journal of Biomedical and Pharmaceutical Research

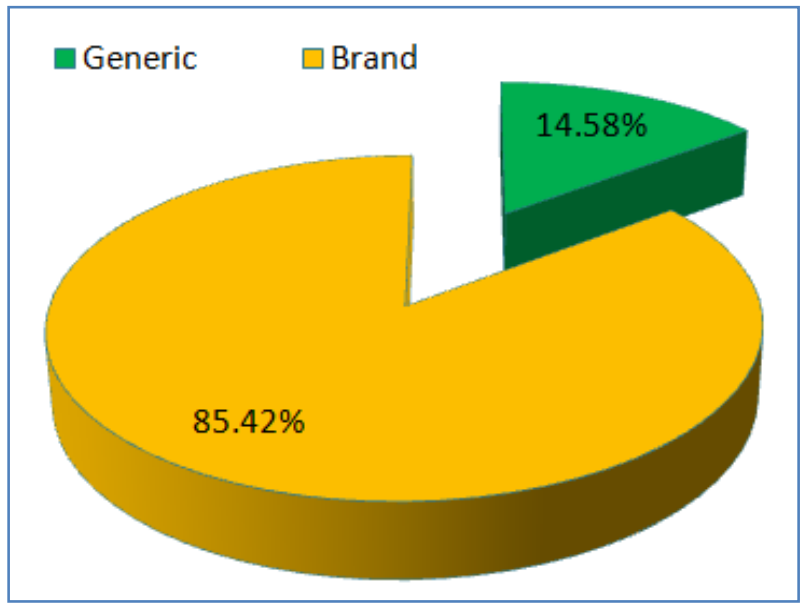

Figure 6: Distribution of drugs on the basis of generic and brand formulation

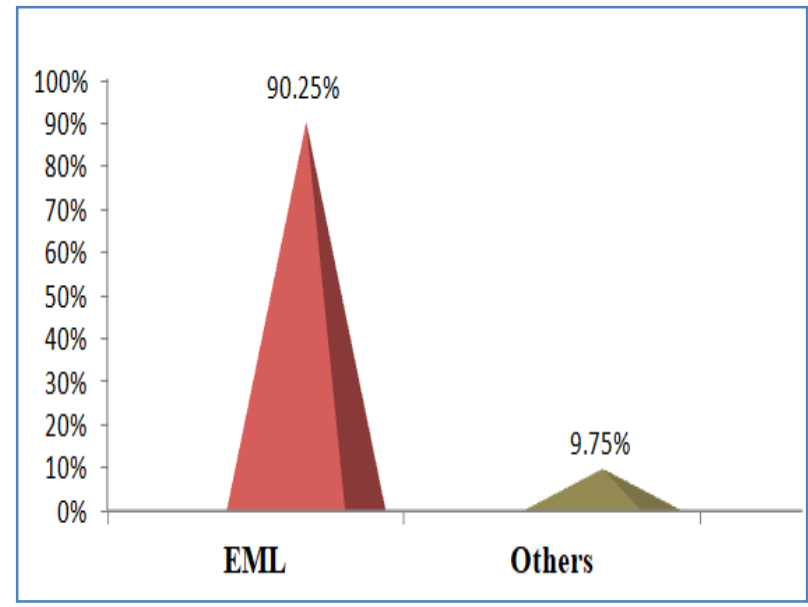

Figure 7: Percentage of EML in C- Section

Table 1: Categorization of patients according to type of caesarean delivery $(n=120)$

\begin{tabular}{|l|l|c|c|}
\hline S. No. & Types of delivery & No. of patients & Percentage \\
\hline 1. & Emergency LSCS & 88 & $73.33 \%$ \\
\hline 2. & Emergency LSCS with B/L TL & 12 & $10 \%$ \\
\hline 3. & Elective LSCS & 15 & $12.50 \%$ \\
\hline 4. & Elective LSCS with B/L TL & 5 & $4.17 \%$ \\
\hline
\end{tabular}

Table 2: Categorization of patients based on length of hospital staying (days) in C- section.

\begin{tabular}{|c|c|c|c|}
\hline S. No. & Stay & No. of patients & Percentage \\
\hline 1 & Less than 1 week (7 days) & 1 & $0.83 \%$ \\
\hline 2 & 2 week (8-14 days) & 109 & $90.83 \%$ \\
\hline 3 & 3 week (15-21 days) & 6 & $5 \%$ \\
\hline 4 & 4 week (22-28 days) & 4 & $3.33 \%$ \\
\hline
\end{tabular}

Table 3: Categorization of patients on the basis of antibiotics prescription in pre-operative orders of C-section

\begin{tabular}{|c|c|c|c|}
\hline S. No. & Drug therapy & No. of patients & Percentage \\
\hline \multirow[t]{3}{*}{1.} & \multicolumn{3}{|l|}{ Single Therapy } \\
\hline & Inj. Ceftriaxone & 64 & $53.33 \%$ \\
\hline & Inj. Amoxicillin with Clavulanic acid & 1 & $0.83 \%$ \\
\hline \multirow[t]{3}{*}{2.} & \multicolumn{3}{|l|}{ Dual Therapy } \\
\hline & Inj. Ceftriaxone and Inj. Metronidazole & 15 & $12.50 \%$ \\
\hline & Inj. Amoxicillin with Clavulanic acid and Inj. Metronidazole & 1 & $0.83 \%$ \\
\hline \multirow[t]{3}{*}{3.} & \multicolumn{3}{|l|}{ Triple Therapy } \\
\hline & Inj. Ceftriaxone, Inj. Metronidazole and Inj. Gentamycin & 7 & $5.83 \%$ \\
\hline & Inj. Ceftriaxone, Tab. Erythromycin and Tab. Metronidazole & 1 & $0.83 \%$ \\
\hline 4. & Others & 31 & $25.83 \%$ \\
\hline
\end{tabular}


Dr. Parminder Nain I et al., Journal of Biomedical and Pharmaceutical Research

Table 4: Categorization of patients on the basis of drug therapy of antibiotics in post-operative orders of C-section.

\begin{tabular}{|c|c|c|c|}
\hline S. no. & Drug Therapy & No. of Patients & Percentage \\
\hline \multirow[t]{4}{*}{1} & \multicolumn{3}{|l|}{ Dual therapy } \\
\hline & Inj. Ceftriaxone and Inj. Metronidazole & 23 & $19.16 \%$ \\
\hline & Tab. Cefixime and Tab. Metronidazole & 2 & $1.66 \%$ \\
\hline & Inj. Amoxicillin with Clavulanic acid and Inj. Metronidazole & 1 & $0.83 \%$ \\
\hline \multirow[t]{6}{*}{2} & \multicolumn{3}{|l|}{ Triple therapy } \\
\hline & Inj. Ceftriaxone, Inj. Metronidazole and Inj. Gentamycin & 75 & $62.50 \%$ \\
\hline & $\begin{array}{l}\text { Inj. Amoxicillin with Clavulanic acid, } \\
\text { Inj. Metronidazole and Inj. Gentamycin }\end{array}$ & 10 & $8.30 \%$ \\
\hline & Tab. Cefixime, Tab. Metronidazole and Inj. Gentamycin & 6 & $5 \%$ \\
\hline & $\begin{array}{l}\text { Inj. Piperacillin with Tazobactum, } \\
\text { Inj. Metronidazole and Inj. Gentamycin }\end{array}$ & 1 & $0.83 \%$ \\
\hline & $\begin{array}{l}\text { Tab. Amoxicillin with Clavulanic acid, Tab. Metronidazole and } \\
\text { Inj. Gentamycin }\end{array}$ & 1 & $0.83 \%$ \\
\hline \multirow[t]{2}{*}{3} & \multicolumn{3}{|l|}{ Quadruple therapy } \\
\hline & $\begin{array}{l}\text { Inj. Ceftriaxone, Inj. Metronidazole, } \\
\text { Inj. Gentamycin and Inj. Amoxicillin with Clavulanic acid }\end{array}$ & 1 & $0.83 \%$ \\
\hline
\end{tabular}

Table 5: Route of antibiotics administration in pre and post-operative orders of C-section

\begin{tabular}{|l|l|c|c|}
\hline \multirow{2}{*}{ S. No. } & \multirow{2}{*}{ Formulation } & \multicolumn{2}{|c|}{ Percentage } \\
\cline { 3 - 4 } & & Pre-operative & Post-operative \\
\hline 1 & Parenteral Route (Injections) & $96.09 \%$ & $59.40 \%$ \\
\hline 2 & Oral Route (Tablets) & $3.91 \%$ & $40.60 \%$ \\
\hline
\end{tabular}

Table 6: Categorization of NSAIDS in post-operative orders of C-section

\begin{tabular}{|l|l|l|l|}
\hline S. No. & NSAIDS & Frequency & Percentage \\
\hline 1. & Inj. Diclofenac sodium & 117 & $48.15 \%$ \\
\hline 2. & Tab. Diclofenac sodium & 6 & $2.46 \%$ \\
\hline 3. & Tab. Diclofenac sodium with serratiopeptidase & 68 & $27.98 \%$ \\
\hline 4. & Tab. Ibuprofen with paracetamol & 42 & $17.28 \%$ \\
\hline 5. & Tab. Paracetamol & 10 & $4.11 \%$ \\
\hline
\end{tabular}

\section{DISCUSSION}

The increasing trend of $\mathrm{C}$-section has generated much controversy regarding the causes of such tendency. Patients' preference for C-section is regarded as a common cause behind increasing elective caesarean delivery rate. ${ }^{12}$ The $\mathrm{C}$-section is done for genuine medical reasons but the number of $\mathrm{C}$-section is increased for many non-medical reason (personal and societal reasons) like good time, favorable day, fear of labour pain (painless delivery), future sexual dissatisfaction, cash or kind for conducting the operation to the health provider and inadequate care during vaginal delivery. ${ }^{13-14}$ Considering merit and demerit of $\mathrm{C}$-section on the criteria mentioned above-drug utilization particularly during hospital stay, expenditure on hospital stay, transport, attendance, nursing etc. ${ }^{15}$ 
This prospective observational studies are designed to review drug use and prescribing patterns of drug pre-operational and post-operational C-section surgery as per the guidelines. A total of 120 cases studied, the mean age of women undergoing Csection surgery was 27 years which was comparable to the other studies finding, the mean age were 33 years. ${ }^{16}$

In the present study, the most common C-section surgery performed was emergency LSCS (73.33\%) which was comparable to the other studies finding (53.63\% to $67.59 \%$ ). In our study, the indications of C-section was fetal distress (28.33\%) which was comparable with other finding that the main reason for C-section was hypothyroidism i.e. $24 \% .{ }^{17}$ Antibiotics were used as a prophylaxis to reduce and prevent the incidence rate of post-operative infection at surgical site which was in accordance with number of other studies. ${ }^{18}$ The third generation cephalosporin's are commonly used alone or in combination with other antibiotic as a prophylaxis to prevent post-operative infection at surgical site. ${ }^{19}$ In this study, single therapy of antibiotic i.e. injection ceftriaxone $\mathbf{( 5 3 . 3 3 \% )}$ was most commonly prescribed followed by dual therapy i.e. injection ceftriaxone with metronidazole to combat the infection as per standard rational antibiotic utilization guideline.

In post-operative C-section procedure, majority of the patients received triple therapy i.e. injection ceftriaxone, inj. metronidazole with injection gentamycin (62.50\%) followed by dual therapy i.e. injection ceftriaxone with injection metronidazole whereas in the other study the most commonly prescribed antibiotic combination was injection metronidazole along with cefotaxime and injection piperacillin with tazobactum and injection ceftriaxone. $^{20}$

In present study, the most common route of antibiotics prescribed was in the form of injection i.e. $96.09 \%$ and $59.40 \%$ as prophylaxis and postoperative respectively and the average number of antibiotics used was 3.5 , this values was much lesser than the average number of antibiotics used in other study. ${ }^{21}$ The prescribers can minimize this by adhering to rational antibiotic utilization.

In C-section most commonly prescribed drug for pain management was injection diclofenac sodium (48.15\%), use of this drug has almost become mandatory following surgery for the management of post-operative pain whereas the other studies concluded that opioid analgesic i.e. tramadol $56 \%$ was most commonly prescribed drug. ${ }^{22}$ Few of studies have shown that use of diclofenac sodium was much preferred than tramadol because tramadol is secreted in the breast milk and substantial quantities may be delivered to the baby if it is consumed by the lactating mother for a long time.

Other prescribed drugs were $\mathrm{H} 2$ - antihistaminics (95.41\%), antiemetic (33.83\%), anti- fibrinolytic (19.93), laxative $(\mathbf{1 . 8 1 \% )}$ which is in contrast with another study $\mathrm{H} 2$ - antihistaminics (98\%), antiemetic (79\%), anti-fibrinolytic (23\%), laxative (11\%). ${ }^{22}$

In our study, $\mathbf{8 5 . 4 2 \%}$ were brand drugs and $\mathbf{1 4 . 5 8 \%}$ were generic drugs, in contrast to our study, the generic drug used by $\mathbf{2 9 . 4 1 \%}$ whereas the brand drugs used were $\mathbf{7 0 . 6 \%}{ }^{[22]}$ The cost of generic drug was less as compare with branded drugs so with the maximum use of generic drugs reduce of cost of post-operative medicines.

Essential drug list was considered $\mathbf{9 0 . 2 5 \%}$ in our study, whereas brand drugs used were $\mathbf{9 . 7 5 \%}$ which is in contrast with another study where $\mathbf{8 7 . 5 \%}$ of the drugs are from essential drug list. $^{22}$

\section{CONCLUSION}

This study was conducted in a tertiary care teaching hospital under the supervision of physician/surgeon of gynaecology and obstetrics department. In this study, the maximum utilized antibiotic was injection ceftriaxone as a single therapy as surgical prophylaxis and injection ceftriaxone, injection metronidazole and injection gentamycin as a triple therapy in post-orders of caesarean section. The commonly prescribed prophylactic and post-operative antibiotic (triple therapy combination) are safe and maximum effective. Other than antibiotics, NSAIDS and antacids were also prescribed by physician/surgeon. Among NSAIDS, injection diclofenac sodium was maximum prescribed and among antacid, injection ranitidine was maximum prescribed in both pre and post-operative orders of caesarean section. As per our study the maximum drugs prescribed by physician/surgeon was branded and from the list of Essential Medicine. Hence, we conclude that the prescribed pattern of antibiotics, NSAIDS and antacids are most effective, safe and rational in the given dose and frequency without any drug interaction in pregnant women. 
All the drugs were prescribed according to FDA category B.

\section{ACKNOWLEDGEMENT}

We are grateful to MMIMSR management and the HOD of Gynaecology and Obstetrics department for allowing and supporting during this study.

\section{REFERENCES}

1. Oinam SJ, Ningthoujam D, Raleng I. A comparative study of the antibiotic utilization during the normal and caesarean section deliveries at Jawaharlal Nehru institute of medical sciences hospital, Imphal, Manipur, India. International Journal of Basic \& Clinical Pharmacology 2016; 5 (3): 794 797.

2. Fauci, Braunwald, Kasper, Harrison's Principles of Internal Medicine, 17th edition, published by Mc Grow Hill Companies, 2008.

3. Rajeshwari H. Drug utilization study in postoperative patients in obstetrics and gynaecology ward of tertiary care hospital. Int J Basic \& Clin Pharmacol 2016; 5: 329-333.

4. Shewade D, Pradhan S. Auditing of prescriptions in a government teaching hospital and four retail medical stores in Pondicherry. Indian J Pharmacol 1998; 30: 408-10.

5. Sangle D, Jadhav RA., Katyare P, Magdum A. A Cross-Sectional, Observational, Prospective Study For Evaluation Of Rational Drugs Used During Pregnancy. International Journal of Pharmacy and Pharmaceutical Sciences 2013; 5(3), 928-930.

6. Thapa RK, Bhandari B, Adhikari K, et al. Antibiotic Prophylaxis in Caesarean Section. International Journal of Public Health Science 2012; 1: 1-5.

7. Tollanes MC. Increased Rate of Caesarean sections: Causes and consequences. Journal of the Norwegian Medical Association 2009; 129(13): 1329-1331.

8. Gudiol F. Surgical antibiotic prophylaxis, tradition and change. Ant J Clin Pract 1998; 95(1): 398-438.

9. Lamont RF, Sobel J, Kusanovic JP, et al. Current Debate on the Use of Antibiotic Prophylaxis for Cesarean Section. An International Journal of Obstetrics and Gynaecology 2011; 118(2), 193201.

10. Nausheen S. Rational use of antibiotics - a quality improvement initiative in hospital setting. Pak Med Assoc 2013; 63(1): 60-64.
11. Gordon SM. Antibiotic prophylaxis against postoperative wound infections. Cleve Clin J Med 2006; 73 (Supply 1): S42-45.

12. MacDorman, MF, Menacker F, Declercq E. "Caesarean Birth in the United States: Epidemology, Trends, and Outcomes". Clin Perinatol 2008; 35: 293-307.

13. McCourt C, Weaver J, Statham H, et al. "Elective Caesarean Section and Decision Making: A Critical Review of Literature". Birth 2007; 34(1): 65-79.

14. Oumachigui, A. "Rising rates of caesarean section: the way ahead". Indian J Med Res 2006; 124: 119122.

15. Kushtagi P, Guruvares. Documenting indication of caesarean deliveries postgraduate. Med. J. 2008; 54 (1): 52-53.

16. Agarwal $M$, Nayeem $M$, Safhi MM, et al. Prescribing pattern of drugs in the department of obstetrics and gynaecology in expecting mothers in Jazan region, KSA. Int J Pharm Pharm Sci 2014; 6 (1):1-4.

17. Kaduskar PU, Dharmalingam M, Kalra $P$. Prepregnancy hypothyroidism versus gestational hypothyroidism: A comparative study, Indian Journal of Endocrinology and Metabolism 2017; 21(5), 660-664.

18. Adu A, Armour CL. Drug utilization review of the third generation cephalosporins. Focus on ceftriaxone, ceftazedime and cefotaxime. Drugs 1995; 50(3): 423-39.

19. Heethal J. Pattern of antimicrobial use in caesarean section in a tertiary care hospital in rural south India. Int J Pharm Biomed Res 2010; 1(2): 57-61.

20. Suseela $T L$, Jaya $S$, Jyothi $S A$, et al. Drug utilization evaluation for post- operative patient in obstetrics and gynaecology department in a tertiary care teaching hospital. World Journal of Pharmacy and Pharmaceutical Sciences 2016; 5(7): 1342-1356.

21. Agrawal JM, Patel NM, Vaniya HV, et al. Drug utilization study in post-operative patients in obstetrics and gynaecology ward of a tertiary care teaching hospital. J Clin Exp Res 2014; 2: 103-109.

22. Divyashree IR., Bhushan A, Tejaswini KJ. Drug utilization study in gynaecological post-operative cases: a retrospective study. European Journal of Pharmaceutical and Medical Research 2017; 4(04): 418-423. 